\title{
Endoscopic ultrasonography-guided antegrade diathermic dilation for the treatment of complete obstruction of a pancreaticogastrostomy
}

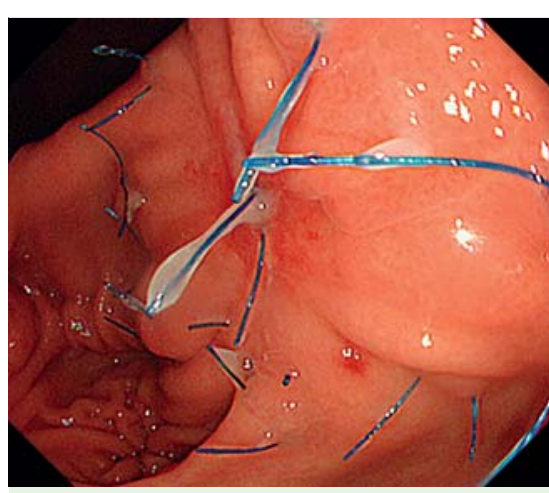

Fig.1 Endoscopic image showing complete obstruction of the pancreaticogastrostomy before diathermic dilation.

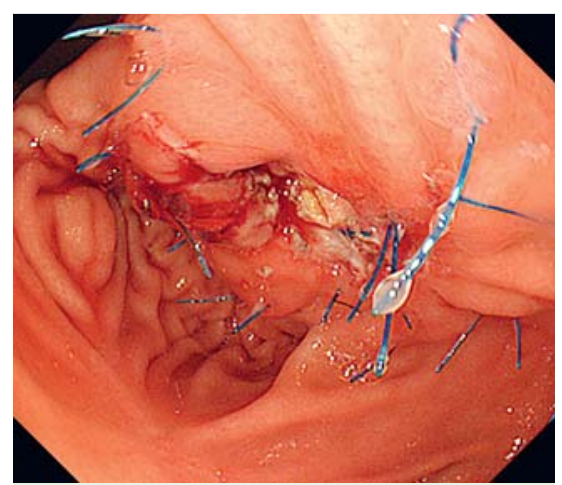

Fig. 2 Endoscopic image after precutting for the anastomosis with a needle knife.

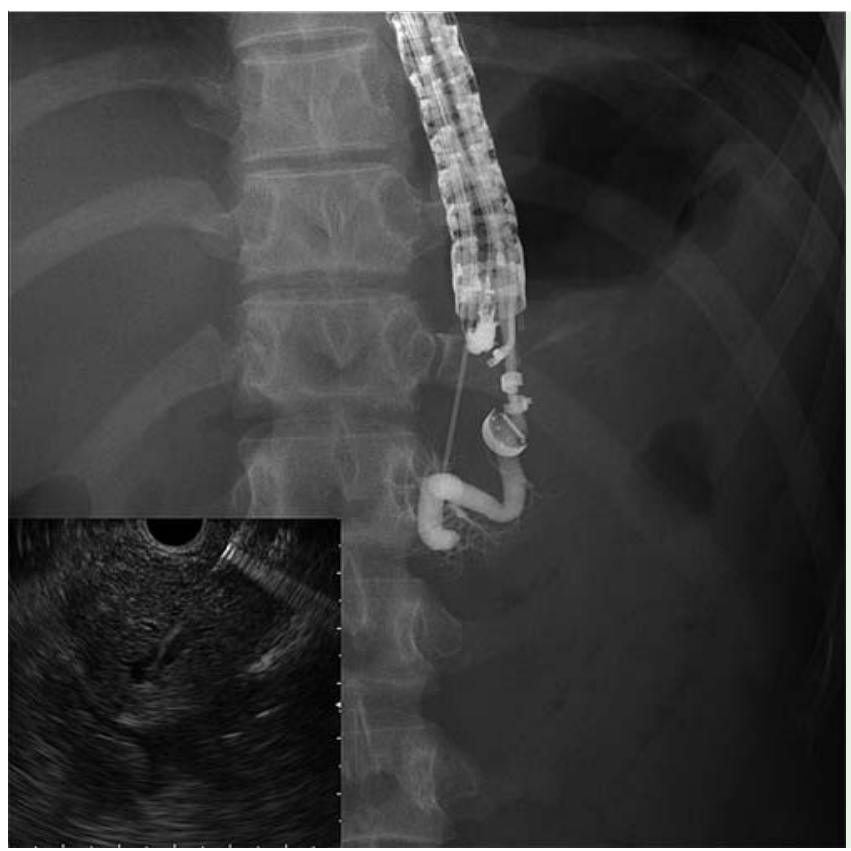

Fig. 3 Radiograph showing the pancreaticogastrostomy obstruction by the endoscopic ultrasoundguided pancreatogram. (Inset: ultrasound view of the 19-gauge needle puncturing the pancreatic duct.)
Endoscopic ultrasonography (EUS)-guided rendezvous is a new and challenging technique. We present a case in which we successfully used a diathermic dilator to treat a complete pancreaticogastrostomy obstruction.

An 18-year-old woman presented to our hospital with acute pancreatitis. She had undergone a duodenum-preserving resection of the pancreatic head 3 months earlier for the treatment of a solid pseudopapillary neoplasm of the pancreas. Esophagogastroduodenoscopy revealed complete pancreaticogastrostomy ob- struction ( Fig. 1). We attempted endoscopic treatment to avoid surgical procedures but could not precut the anastomosis with a needle knife because the orifice of the pancreatic duct could not be detected ( Fig. 2). Subsequently, we performed the EUS-guided rendezvous procedure. Using a 19-gauge needle, we punctured the pancreatic duct and placed a 0.025inch guidewire ( Fig.3, Video 1). An ultra-tapered endoscopic retrograde cholangiopancreatography catheter and a 6-Fr wire-guided diathermic dilator (blended cut mode; Cysto-Gastro-Set;
Endo-Flex, GmbH, Voerde, Germany) were used to dilate the needle tract ( $\bullet$ Video 1). Dilation of the tract was successful, but neither a 0.035 -inch nor a 0.025 -inch guidewire could be passed through the pancreaticogastrostomy obstruction ( Video 1). Computed tomography showed the pancreas attached to the stomach and the axis of the pancreatic duct crossing the gastric wall. We used the diathermic dilator to pierce the obstruction and obtain transgastric access to place a guidewire in the stomach ( Fig.4, - Video 1). Afterward, we exchanged the echoendoscope for a duodenoscope. Finally, a retrograde 7-Fr plastic stent was placed across the obstruction following diathermic and balloon dilation of the tract without serious complications (๑ Fig. 5, Video 2).

One of the most common problems encountered during EUS-guided rendezvous is difficulty placing a guidewire across the obstruction [1]. We have reported the use of transpapillary and EUS-guided diathermic dilation for severe, refractory benign or malignant strictures of the bile and pancreatic ducts [2-5]. Used with caution, diathermic dilation is useful to treat complete obstruction of a pancreaticogastrostomy that cannot be pierced with conventional techniques.

Endoscopy_UCTN_Code_TTT_1AS_2AD

Competing interests: None

Hiroshi Kawakami, Masaki Kuwatani, Kazumichi Kawakubo, Yoshimasa Kubota, Yoko Abe, Shuhei Kawahata, Kimitoshi Kubo, Naoya Sakamoto

Department of Gastroenterology and Hepatology, Hokkaido University Graduate School of Medicine, Sapporo, Japan

\section{Video 1}

Endoscopic ultrasonography-guided rendezvous procedure in which antegrade diathermic dilation is used to treat complete obstruction of a pancreaticogastrostomy.

\section{Video 2}

Retrograde pancreatic stenting across the obstruction following diathermic and balloon dilation of the tract. 

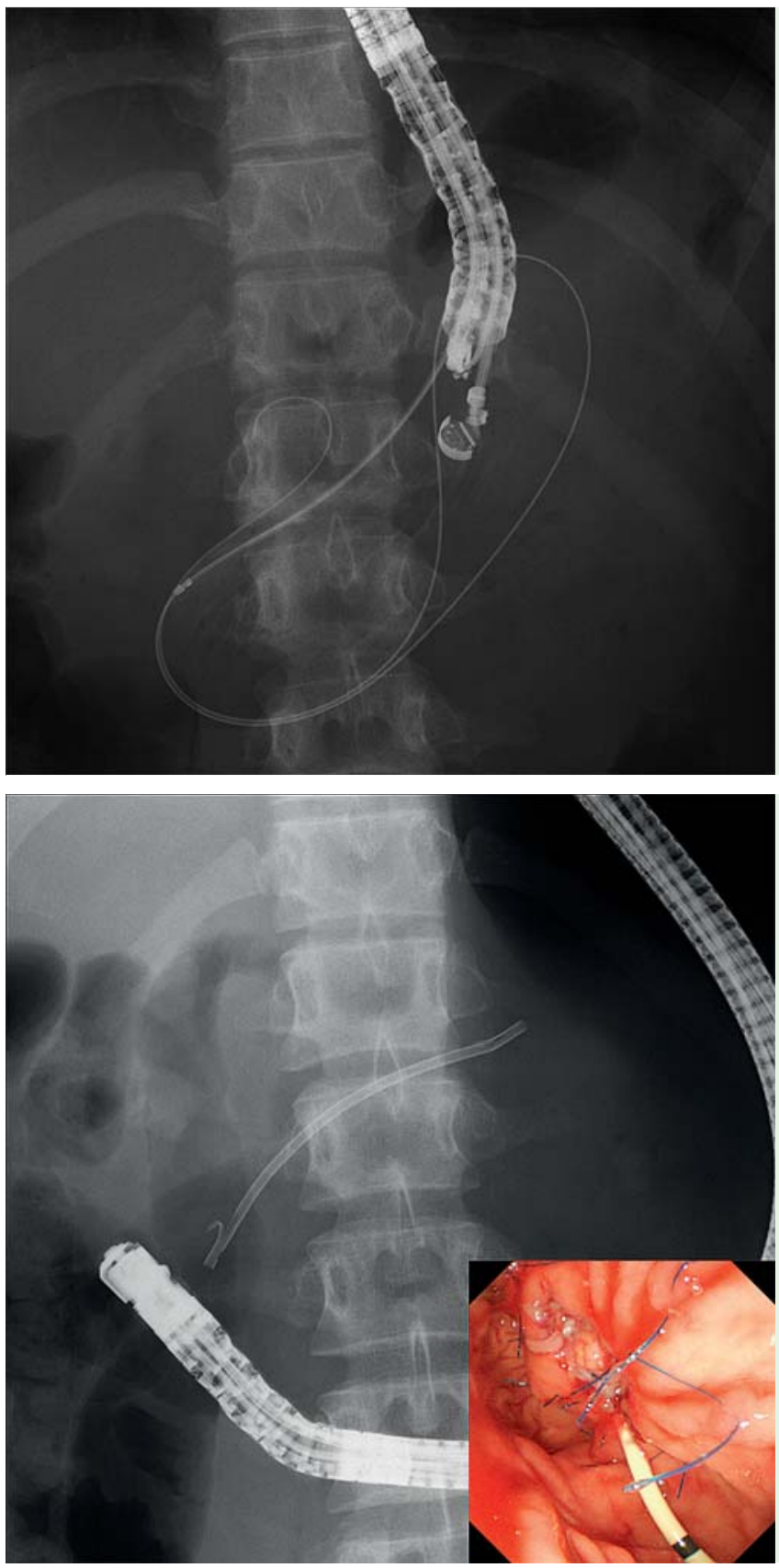

Fig.4 Radiograph showing the pancreaticogastrostomy obstruction successfully traversed with the diathermic dilator.

Fig. 5 Radiograph showing pancreatic stent placement across the pancreaticogastrostomy obstruction. (Inset: endoscopic view of the pancreatic stent.)

\section{References}

1 Fujii LL, Topazian MD, Abu Dayyeh BK et al. EUS-guided pancreatic duct intervention: outcomes of a single tertiary-care referral center experience. Gastrointest Endosc 2013; 78: 854-864.e1

2 Kawakami H, Kuwatani M, Eto K et al. Resolution of a refractory severe biliary stricture using a diathermic sheath. Endoscopy 2012; 44 (Suppl. 02): E119-E120

3 Kawakami H, Kuwatani M, Kawakubo Ket al. Transpapillary dilation of refractory severe biliary stricture or main pancreatic duct by using a wire-guided diathermic dilator (with video). Gastrointest Endosc 2014; 79 : $338-343$

4 Kawakami H, Kuwatani M, Sakamoto N. Endoscopic ultrasound-guided antegrade diathermic dilation followed by self-expandable metallic stent placement for anastomotic stricture after hepaticojejunostomy (with video). Dig Endosc 2014; 26: 121 - 122

5 Kawakami H, Kuwatani M, Kawakubo Ket al. Endoscopic ultrasound-guided antegrade diathermic dilation followed by self-expandable metallic stent placement for malignant distal biliary stricture. Endoscopy. In press 2014

\section{Bibliography}

DOI http://dx.doi.org/

10.1055/s-0034-1377600

Endoscopy 2014; 46: E517-E518

(c) Georg Thieme Verlag KG

Stuttgart · New York

ISSN 0013-726X

\section{Corresponding author}

\section{Hiroshi Kawakami, MD, PhD}

Department of Gastroenterology and Hepatology Hokkaido University Graduate School of Medicine Kita 15, Nishi 7, Kita-ku

Sapporo 060-8638

Japan

Fax: +81-11-706-7867

hiropon@med.hokudai.ac.jp 